\title{
PEMBANGUNAN SUMBER DAYA MANUSIA PADA SEKOLAH KEJURUAN DI INDONESIA: TANTANGAN DAN PELUANG DI ERA REVOLUSI INDUSTRI 4.0
}

\author{
Mahmud Ridwan \\ SMKN 1 Rangas Mamuju, Sulawesi Barat, Indonesia \\ machmud69@gmail.com
}

\begin{abstract}
Abstrack
Vocational education is one of education that is unique in the orientation of creating work-ready people with the appropriate knowledge and skills. World changes in the era of the industrial revolution 4.0, provide new direction in enhancing human resource in the form of new challenges. This research was conducted to see the challenges and opportunities that exist in the industrial era 4.0 related to the development of human resource in vocational education in Indonesia. The study in this research used the literature method. Literature study is used to see the literature related to the subject. From this topic, conclusion were drawn, so that it can be seen some of the challenges that exist in Industry 4.0. but behind that, there are also opportunities that vocational education has that can be maximally utilized in building quality human resource.
\end{abstract}

keywords: human resources development, vocational school, industrial revolution 4.0

\begin{abstract}
Abstrak
Pendidikan vokasi merupakan salah satu pendidikan yang unik dalam orientasi menciptakan manusia yang siap kerja dengan pengetahuan dan keterampilan yang sesuai. Perubahan dunia di era revolusi industri 4.0, memberikan arah baru dalam peningkatan sumber daya manusia berupa tantangan baru. Penelitian ini dilakukan untuk melihat tantangan dan peluang yang ada di era industri 4.0 terkait dengan pengembangan sumber daya manusia pada pendidikan vokasi di Indonesia. Penelitian ini menggunakan metode kepustakaan. Studi literatur digunakan untuk melihat literatur-literatur yang berkaitan dengan pokok bahasan. Dari topik tersebut diambil kesimpulan, sehingga dapat diketahui beberapa tantangan yang ada di Industri 4.0. namun dibalik itu, terdapat pula peluang yang dimiliki pendidikan vokasi yang dapat dimanfaatkan secara maksimal dalam membangun sumber daya manusia yang berkualitas.
\end{abstract}

Kata kunci: pembangunan SDM, Sekolah Kejuruan, revolusi industry 4.0. 


\section{Pendahuluan}

Memasuki abad ke-21 ditandai dengan abad keterbukaan informasi atau globalisasi yang serba digital. Era ini disebut juga sebagai era digital yang artinya kehidupan manusia memiliki perubahan-perubahan secara fundamental dibandingkan dengan era sebelumnya. Disebut sebagai era digital karena kehiduan manusia serta keterbukaan informasi yang terus merambah melalui aspek digitalisasi, tentunya hal tersebut pula dengan sendirinya menjadi era yang meminta sumber daya manusia yang berkualitas. Hal tersebut menjadi sebuah tuntutan baru yang yang membutuhkan terobosan-terobosan berpikir, penyusunan konsep serta tindakan, atau dengan kata lain membutuhkan paradigma baru untuk menghadapi tantangan tersebut. Tantangan yang baru menuntut proses terobosan pemikiran (breakthrough thinking process) apabila yang diinginkan adalah output yang bermutu yang dapat bersaing dengan hasil karya dalam dunia yang serba terbuka. ${ }^{1}$

Perubahan zaman menjadi sebuah keniscayaan bagi kehidupan manusia. Sejarah mencatat perubahan sosial yang kemudian terjadi pada saat ini, telah memasuki era industri 4.0. Era ini merupakan transformasi dari fase revolusi 1.0, kemudian revolusi 2.0 dan revolusi 3.0. Kehadiran dari revolusi industri 4.0 ini merupakan perubahan nyata yang ditandai dengan penggabungan 3 aspek penting dalam produksi yakni manusia, mesin, dan big data (Rezasyah, 2018). Pada era ini terjadi disrupsi yang dapat diartikan sebagai pergesaran aktivitas manusia dari dunia nyata ke dunia maya melalui otomatisasi dan konektivitas pergerakan yang tidak linear menggunakan tenaga robot dan teknologi. ${ }^{2}$

Dengan demikian, dapat dilihat bahwa faktor produksi di era ini yang memiliki peningkatan dimana tenaga manusia dapat digantikan dengan mesin. Oleh karena itu, manusia perlu melakukan adaptasi secara total dalam menyikapi perubahan tersebut. Terlebih saat ini, sumberdaya manusia mesti mempersiapkan diri melalui peningkatan kapasitas diri, karena di masa mendatang, persaingan akan semakin ketat. Oleh sebab itu, manusia mesti dapat beradaptasi dengan total untuk menyikapi perubahan tersebut, serta mampu mempersiapkan diri dengan melakukan peningkatan kapasitas diri.

Peningkatan kapasitas diri ataupun pengembangan sumber daya manusia sebagai keunggulan suatu bangsa tak lepas dari pendidikan yang mampu menjawab tantangan-tantangan zaman yang sangat cepat. Pendidikan menduduki posisi sentral dalam nadi kehidupan berbangsa karena berperan sebagai pencetak sumber daya manusia. Oleh karenanya, pendidikan juga merupakan alur tengah pembangunan dari seluruh sektor pembangunan pada bangsa ini. Salah satu bentuk pendidikan yang

1 Tilaar, H.A.R. (1998). Beberapa agenda reformasi pendidikan nasional dalam perspektif abad 21. Penerbit Tera Indonesia.

${ }^{2}$ Himawati, I. P., Nopianti, H., \& Widiyarti, D. (2020). "Sosialisasi Pengetahuan Mengenai Peluang Dan Tantangan Di Era Revolusi Industri 4.0 Pada Pelajardi Sekolah Menengah Atas Dan Kejuruan Di Kota Bengkulu”. Jurnal. Widya Laksana, 9(2), 205-212. 
berorientas pada penyiapan sumber daya manusia yang berkualitas adalah pendidikan kejuruan yang salah satunya dilaksanakan pada sekolah tingkatan menengah yang bernama sekolah menengah kejuruan (SMK) Atau Madrasah Aliyah Kejuruan (MAK).

Pendidikan kejuruan menurut beberapa ahli adalah merupakan faktor kunci dalam bidang perekonomian negara, persaingan atau bahkan stabilitas negara. Hal itu disebabkan oleh kepercayaan tentang keberhasilan pendidikan kejuruan dan menghasilkan tenaga kerja yang terampil adalah bagian yang penting dalam pengembangan sumberdaya manusia untuk memberikan bekal pengetahuan dan keterampilan kepada masyarakat sesuai dengan keperluan dunia kerja dan industri.

Tujuan pendidikan menengah kejuruan sendiri menurut Undang-undang Nomor 20 Tahun 2003, terbagi menjadi tujuan umum dan tujuan khusus. Tujuan umum pendidikan menengah kejuruan adalah untuk (a) meningkatkan keimanan dan ketakwaan peserta didik kepada Tuhan Yang Maha Esa; (b) mengembangkan potensi peserta didik agar menjadi warga Negara yang berakhlak mulia, sehat, berilmu, cakap, kreatif, mandiri, demokratis dan bertanggung jawab; (c) mengembangkan potensi peserta didik agar memiliki wawasan kebangsaan, memahami dan menghargai keanekaragaman budaya bangsa Indonesia; dan (d) mengembangkan potensi peserta didik agar memiliki kepedulian terhadap lingkungan hidup dengan secara aktif turut memelihara dan melestarikan lingkungan hidup, serta memanfaatkan sumber daya alam dengan efektif dan efisien. ${ }^{3}$

Di era revolusi industri 4.0 ini sendiri, SMK memiliki peluang serta tantangannya tersendiri dalam mengembangkan sumber daya manusia yang kompleks. Pendidikan kejuruan juga diarahkan untuk dapat meningkatkan kemandirian individu dalam membangun usahanya sendiri atau berwirausaha sesuai dengan kompetensi yang dimilikinya. Salah satu kebijakan pemerintah adalah revitalisasi pendidikan kejuruan Indonesia. Dukungan pemerintah mencakup : sistem pembelajaran, satuan pendidikan, peserta didik, dan pendidik dan tenaga kependidikan juga dibutuhkan. Sistem pendidikan membutuhkan gerakan kebaruan untuk merespon era industri 4.0. Salah satu gerakan yang dicanangkan oleh pemerintah adalah gerakan literasi baru sebagai penguat bahkan menggeser gerakan literasi lama. Gerakan literasi baru yang dimaksudkan terfokus pada tiga literasi utama yaitu : literasi digital, literasi teknologi, dan literasi manusia. ${ }^{4}$

Selain keharusan untuk menguasai kompetensi sesuai dengan bidangnya, lulusan SMK juga diharapkan mampu melakukan pengembangan diri untuk dapat berkompetisi pada kebutuhan pasar kerja. Oleh karena itu, penting kiranya untuk

\footnotetext{
Nasional

${ }^{3}$ Depdiknas. 2003. Undang-undang RI Nomor 20, Tahun 2003, tentang Sistem Pendidikan

${ }^{4}$ Putih, S. S. T. "Global 4 Dalam Menghadapi Revolusi Industri 4.0.”
} 
mengetahui bagaiman peluang dan tatangan di era revolusi industi 4.0 dalam membangun sumber daya manusia pada pendidikan kejuruan di indonesia.

\section{Metode}

Penelitian ini merupakan penelitian kepustakaan. Yaitu mengkaji literaturliteratur ilmiah baik berupa buku, artikel, jurnal, prosiding, maupun hasil-hasil konferensi yang mengkaji topik berkenaan dengan pendidikan kejuruan di Indonesia di era revolusi industri 4.0 guna untuk menarik sebuah hasil ilmiah mengenai peluang dan tantangan terhadap pengembangan sumber daya manusia di era revolusi industri 4.0 pada sekolah kejuruan di Indonesia.

\section{Hasil dan Pembahasan \\ Pendidikan Kejuruan di Indonesia}

Pengembangan sumber daya manusia merupakan tanggung jawab bersama yang harus dilakukan terutama dalam bidang pendidikan. Salah satu pendidikan yang memfokuskan pada pengembangan sumber daya manusia yang berkualitas adalah pendidikan kejuruan. Pengembangan pendidikan kejuruan/vokasi sendiri juga membutuhkan kerjasama, dukungan dan partisipasi penuh dari organisasi-organisasi pemerintah dan non pemerintah agar terbentuk konsensus diantara stakeholder. ${ }^{5}$ Keterlibatan seluruh elemen dalam pendidikan kejuruan tersebut dimaksudkan agar dapat mengatasi masalah-masalah yang terjadi baik berupa perubahan sosial masyarakat, perubahan lingkungan, perubahan ekonomi dan politik ataupun perubahan teknologi.

Di Indonesia ada 5 jenis pendidikan kejuruan yang terdiri dari: (1) Sekolah Menengah Kejuruan dan Madrasah Aliyah Kejuruan, (2) Akademi Komunitas; (3) Politeknik, (4) Universitas, dan (5) Balai Latihan Kerja Tujuan pendikan kejuruan sendiri adalah agar terbentuknya kompetensi, berkembangnya pegetahuan, kempuan serta keterampilan dari peserta didik, ${ }^{6}$ sehingga diharapkan individu mampu belajar secara menyeluruh dari pengalaman yang diperoleh melalui magang, dengan begitu individu mampu melakukan pekerjaan dengan baik. ${ }^{7}$

Tahun 2015 pemerintah begitu menyadari pentingnya pendidikan kejuran dalam hal ini SMK dengan SMA yang sebelum itu menjadi prioritas sehingga pemerintahpun kembali menegaskan perubahan rasio yang pada awalnya SMA sebesar 70\% sedangkan SMK sebesar 30\%, berbalik menjadi SMA sebesar 70\% dan SMA menjadi 30\%. Hal tersebut dilakukan dengan maksud untuk mendorong keluaran (lulusan) mejadi lebih relevan dengan tuntutan kebutuhan kerja dengan potensi dan kualitas yang memiliki keunggulan kompetitif baik di kancah nasional maupun internasional. Hal tersebut sangat mungkin terjadi karena pendidikan

${ }^{5}$ Hiniker, L., \& Putnam, R. A. (2009). Partnering to meet the needs of a changing workplace. In International handbook of education for the changing world of work (pp. 203-217). Springer, Dordrecht.

${ }^{6}$ Maysitoh, M., Agung, D. F., \& Afdal, A. (2018). Pendidikan Kejuruan di Era Industri 4.0: Tantangan dan Peluang Karier. Schoulid: Indonesian Journal of School Counseling, 3(3), 89-96.

${ }^{7}$ Divayana, D. G. H., Suyasa, P. W. A., Ariawan, I. P. W., Mahendra, I. W. E., \& Sugiharni, G. A. D. (2019, February). The design of digital book content for assessment and evaluation courses by adopting superitem concept based on Kvisoft Flipbook Maker in era of industry 4.0. In Journal of Physics: Conference Series (Vol. 1165, No. 1, p. 012020). IOP Publishing. 
kejuruan memang menjadi lembaga yang dipersiapkan untuk dapat mengakomodir kebutuhan pasar dan meningkatkan ekomi dalam masyarakat dengan mengangkat potensi unggul lokal menjadi daya saing bangsa.

Pemerintah pada Juni 2020 melalui kementrian pendidikan dan kebudayaan (kemendikbud) merencanakan akan mengubah sistem pendidikan lama di sekolah menengah kejuruan yang dari 3 tahun menjadi 4 tahun lamanya dengan harap siswa dapat menguasai tekhnik operasional secara utuh serta meningkatkan citra profesional lulusan SMK di dunia usaha dan/atau dunia industri (DUDI). ${ }^{8}$ Perubahan tersebut dilakukan untuk menyelaraskan kurikulum SMK dengan kebutuhan DUDI saat ini karena proses pendidikan tersebut digabungkan dengan magang sehingga dianggap ideal untuk dpat meningkatkan efisiensi dan relevansi antara SMK dengan DUDI karena telah dilengkapi dengan keterampilan sesuai yang diingikan oleh dunia usaha dan dunia industri.

Dapat dilihat bahwa pendidikan kejuruan yang ada di Indonesia kemudian dari tahun ke tahun terus mendapatkan perhatian dari berbagai pihak. Hal tersebut tentunya merupakan hal yang positif mengingat bahwa pendidikan kejuruan merupakan salah satu pembangun sumber daya manusia yang berkualitas dikarenakan pada dasarnya pendidikan kejuruan menghendaki terciptanya lulusan yang mampu dan mau bekerja pada bidang yang telah digelutinya selama menempuh pendidikan. ${ }^{9}$

\section{Tantangan dan Peluang di Era Revolusi Industri 4.0}

Aktifitas manusia di dunia ada pada skala, ruang hidup, konpleksitas dan transformasi kehidupan yang telah dialami sebelumnya. Bahkan manusia bisa saja ada pada kehidupan yang tidak pasti, olehnya itu manusia harus mampu untuk merespon secara cepat perubahan yang terjadi secara terintegrasi dan komprehensif dengan melibatkan seluruh komponen global sehingga tantangan di era revolusi industri 4.0 dapat diubah menjadi sebuah peluang.

Memasuki era revolusi industri 4.0 maka sekolah kejuruan mendapatkan tantangan untuk dapat melakukan pembaharuan ataupun perubahan di beberapa sektor agar mampu untuk menghasilkan sumber daya manusia yang mampu bersaing di dunia kerja. Tantangan revolusi industri 4.0 bukan hanya persaingan antar tenaga kerja manusia melainkan dengan mesin, ${ }^{10}$ bahkan keunikan tersendiri dari revolusi 4.0 adalah munculnya kecerdasan buatan yang diperkirakan akan berpengaruh terhadap peran manusia dalam suatu industri.

Wolter mengidentifikasi tantangan industri 4.0 sebagai berikut; a) masalah keamanan teknologi informasi; b) keandalan dan stabilitas mesin produksi; c) kurangnya keterampilan yang memadai; d) keengganan untuk berubah oleh para pemangku kepentingan; dan e) hilangnya banyak pekerjaan karena berubah menjadi otomatisasi. ${ }^{11}$

8 Andina, E. (2020). Eksplorasi Sikap Pembaca terhadap Wacana Kebijakan Program Pendidikan Kejuruan Empat Tahun. Aspirasi: Jurnal Masalah-masalah Sosial, 11(2), 135-155.

${ }^{9}$ Mourtzis, D., Vasilakopoulos, A., Zervas, E., \& Boli, N. (2019). Manufacturing system design using simulation in metal industry towards education 4.0. Procedia Manufacturing, 31, 155-161

10 Kholiq, A. et al. (2020) "Sosialisasi Dan Pendampingan Siswa/Siswi Smk Teratai Putih Global 4 Dalam Menghadapi Revolusi Industri 4.0". Jurnal Abdimas USNI, 1(1).

11 Muhammad, Y. (2018). Era Industri 4.0: Tantangan dan Peluang Perkembangan Pendidikan Kejuruan Indonesia. 
Irianto kemudian menjelaskan tantangan industri 4.0 yaitu; (a) kesiapan industri; (b) tenaga kerja terpercaya; (c) kemudahan pengaturan sosial budaya; dan (d) diversifikasi dan penciptaan lapangan kerja dan peluang industri 4.0 yaitu; (1) inovasi ekosistem; (2) basis industri yang kompetitif; (3) investasi pada teknologi; dan (4) integrasi Usaha Kecil Menengah (UKM) dan kewirausahaan. ${ }^{12}$

Tantangan dari industri 4.0 tersebut akan dapat mendorong Sekolah kejuruan untuk semakin berinovasi dan berkreasi dalam pengembangan sumber daya manusia. Pemerintah juga memegang andil yang cukup besar untuk dapat meninjau relevansi antara pendidikan kejuruan dengan dunia pekerjaan untuk dapat merespon tantangan tersebut dengan tetap memperhatikan aspek kemanusiaan, bahwa dengan industri 4.0 ini maka tatangan sekolah kejuruan akan semakin kompleks.

Tantangan-tantangan tersebut harus pula direspon secara cepat dan taggap agar sekolah kejuruan dapat menghasilkan lulusan yang tidak lagi menambah jumlah pengangguran di negeri ini seperti yang terjadi pada tahun 2017 dimana jumlah pengangguran yang berasal dari Sekolah Menengah Kejuruan (SMK) menduduki peringkat teratas yaitu sebesar $9,27 \%{ }^{13}$

Untuk menjawab tantangan tersebut maka sekolah kejuruan harus memiliki beberapa karakteristik yaitu: 1) kinerja individu berorientasi dalam dunia kerja; 2) penilaian khusus pada kebutuhan nyata di lapangan; 3) kurikulum berfokus pada aspek psikomotorik, afektif, dan kognitif; 4) sekolah bukan menjadi satu-satunya tempat tolak ukur dari keberhasilan; 5) kepekaan terhadap perkembangan dunia kerja; 6) sarana dan prasarana yang memadai; dan 7) adanya dukungan masyarakat. ${ }^{14}$

Sekolah kejuruan adalah pendidikan yang berorientasi pada pengembangan proses dan hasil pembelajaran. ${ }^{15} \mathrm{Hal}$ tersebut karena pendidikan kejuruan merupakan tempat menempa kematangan dan keterampilan seseorang sehingga tidak bisa hanya dibebankan kepada suatu kelompok melainkan menjadi tanggung jawab bersama. ${ }^{16}$ Sehingga pelatihan kejuruan dan akuisisi keterampilan sangat berpengaruh terhadap pengembangan identitas seseorang terhadap suatu pekerjaan. ${ }^{17}$

Pendidikan kejuruan memang difokuskan untuk menyediakan tenaga kerja yang terampil pada berbagai sektor seperti perindustiran, pertanian dan teknologi untuk meningkatkan pembangunan ekonomi, ${ }^{18}$ pendidikan kejuruan juga diarahkan dalam

${ }^{12}$ Irianto, D. (2017). Industry 4.0 The Challenges of Tomorrow. Batu malang.

Kholiq, A. et al. (2020) "Sosialisasi Dan Pendampingan Siswa/Siswi Smk Teratai Putih Global 4 Dalam Menghadapi Revolusi Industri 4.0". Jurnal Abdimas USNI, 1(1).

13 Muhammad, Y. (2018). Era Industri 4.0: Tantangan dan Peluang Perkembangan Pendidikan Kejuruan Indonesia.

${ }^{14}$ Bukit, M. (2014). Strategi dan inovasi pendidikan kejuruan dari kompetensi ke kompetisi. Bandung: Alfabeta.

15 Sutiyatno, S. (2015) 'Pentingnya pendidikan kejuruan berorientasi pasar tenaga kerja'.

16 Edmon, A., \& Oluiyi, A. (2014). Re-engineering technical vocational education and training toward safety practice skill needs of sawmill workers against workplace hazards in Nigeria [Versi elektronik]. Journal of Education and Practice, 5(7), 150-157.

${ }^{17}$ Brown, A., Kirpal, S., \& Rauner, F. (2007). Identitas at work. Netherlands: Springer.

18 Afwan, M. (2013). Leadership on technical and vocational education in community college [Versielektronik]. Journal of Education and Practice, 4 (21), 21-23. 
rangkan meningkatkan kemandirian individu untuk berwirausaha sesuai dengan kompetensi atau kemampuan yang dimiliki. ${ }^{19}$

Menghadapi industri 4.0, pendidikan kejuruan juga membutuhkan dukungan masyarakat. Hal ini akan meningkatkan kepercayaan diri lulusan pendidikan kejuruan sehingga lulusannya merasa aman sebagai pekerja yang terampil karena adanya dukungan dan pengakuan dari masyarakat. ${ }^{20} \mathrm{Hal}$ itu karena pendidikan kejuruan merupakan pendidikan menengah yang mempersiapkan peserta didik terutama untuk bekerja dalam bidang tertentu. ${ }^{21}$ Dalam fungsinya, pendidikan kejuruan memiliki fungsi untuk mempersiapkan manusia seutuhnya yang mampu meningkatkan kualitas hidup, dapat mengembangkan dirinya, serta mempunyai keahlian dan keberanian untuk menciptakan peluang meningkatkan penghasilan. (Prasetyo A., 2019). ${ }^{22}$

Dari asumsi di atas maka dapat dilihat bahwa pendidikan atau sekolah kejuruan merupakan pendidikan yang unik karena berorientasi atau berfokus pada pengembangan sumber daya manusia yang siap berkompetisi di dunia industri. Hal tersebut juga dapat dilihat bahwa pendidikan kejuruan memiliki beberapa kelebihan dibandingkan dengan sekolah pada umunya yaitu: a) Skill intensi; b) Menghadapi globalisasi perdagangan dan investasi; c) Tenaga terampil; d) Pendidikan kejuruan memiliki multi fungsi; dan e) Pendidikan kejuruan berwawasan link-and-match. ${ }^{23}$

Berdasarkan teori-terori yang ada di atas, maka dapat disimpulkan bahwa pendidikan kejuruan memiliki peluang dalam meningkatkan sumber daya manusia dan menjawab tantangan era revolusi industri 4.0. Tantangan tersebut harus ditanggapi dengan cepat dan tepat karena dalam peningkatan sumber daya manusia maka sinergi antar elemen harus terbangun dalam menetapkan standar profesionalisme di masing-masing sektor. Pemerintah sendiri dalam merespon tantangan industri 4.0, pengangguran, dan bonus demografi, fokus dengan meningkatkan kualitas sumber daya manusia melalui pendidikan kejuruan dan kebijakan lintas kementrian serta lembaga degan mengeluarkan kebijakan yang salah satunya adalah revitalisasi pendidikan kejuruan Indonesia. Respon dan kebijakan pemerintah dalam merevitalisasi pendidikan kejuruan harus meliputi 4 hal yaitu peserta didik, sistem pembelajaran, satuan pendidikan, pendidik dan tenaga kependidikan. ${ }^{24}$

Untuk mencapai empat hal tersebut maka perlu adanya gerakan pembaharuan termasuk dengan penyelarasan muatan pembelajaran dengan pemenuhan keterampilan di era industri 4.0 yang meliputi 1) pembelajaran dan keterampilan inovasi dengan mencakup penguasan pengetahuan dan keterampilan yang beraneka

${ }_{19}$ Kennedy, O.O. (2011). Philosophical and sociological overview of vocational-technical education in Nigeria [Versi elektronik]. Journal of Academic Research in Business and Social Sciences, $1,167-175$.

20 Prasetyo, A. (2019, May). Peran Pendidikan Kejuruan Dalam Menghadapi Era Industri 4.0. In Seminar Nasional Pendidikan Teknik Otomotif (Vol. 3, No. 1).

${ }^{21}$ Sudira, P. (2012). Filosofi \& Teori Pendidikan Vokasi dan Kejuruan. Yogyakarta: UNY Press.

22 Prasetyo, A. (2019, May). Peran Pendidikan Kejuruan Dalam Menghadapi Era Industri 4.0. In Seminar Nasional Pendidikan Teknik Otomotif (Vol. 3, No. 1).

23 Wonggo, D. (2012). Tantangan Pendidikan Kejuruan dalam Era Perdagangan Bebas. Prosiding APTEKINDO, 6(1).

${ }^{24}$ Maysitoh, M., Agung, D. F., \& Afdal, A. (2018). Pendidikan Kejuruan di Era Industri 4.0: Tantangan dan Peluang Karier. SCHOULID: Indonesian Journal of School Counseling, 3(3), 89-96. 
ragam, berfikir kritis dan penyelesaian masalah, komunikasi dan kolaborasi, dan kreatifitas dan inovasi, 2) keterampilan literasi digital mencakup literasi informasi, literasi media, dan literasi ICT, 3) karir dan kecakapan hidup meliputi fleksibilitas dan adaptabilitas, inisiatif, interaksi sosial dan budaya, produktifitas, akuntabilitas, kepemimpinan serta tanggung jawab. ${ }^{25}$ (Arifin, I. 2018)

Salah satu program pemerintah adalah pembaruan gerakan literasi dengan fokus utama pada literasi digital, literasi teknologi dan literasi manusia. Tiga fokus utama ini dianggap sebagai sebuah keterampilan yang begitu dibutuhkan di era 4.0 ini terutama berkaitan dengan literasi digital yang sangat relevan dengan kebaruan dan percepatan proses informasi di dunia digital sekarang ini. Sehingga diharapkan dengan gerakan kebaruan tersebut akan menciptakan peserta didik dan lulusanlulusan yang mampu berkompetisi dan cepat tanggap dengan semua yang terjadi secara cepat, dengan demikian maka akan tercipta sumber daya manusia yang unggul serta terampil dalam memanfaatkan teknologi, berfikir kritis, terampil dalam bekerja sama, dan memiliki kesadaran sosial.

\section{Kesimpulan}

Era revolusi industri 4.0 membawa perubahan yang begitu besar di segala aspek kehidupan tak terkecuali di dunia pendidikan. Salah satunya adalah pendidikan kejuruan sebagai salah satu instansi pembangun sumber daya manusia. Dari penelitian ini dapat ditarik kesimpulan bahwa ada begitu bayak tantangan dalam pengembangan sumber daya manusia di era industri 4.0 yang menuntut penguasaan atas tekhnologi sampai kepada persaingan dunia kerja antara manusia dengan mesin. Namun, di lain sisi terdapat pula banyak peluang yang harus mampu dimanfaatkan oleh pendidikan kejuruan dalam rangka mencetak SDM yang unggul serta kompetitif dalam persaingan dunia kerja dan industri yang ditawarkan oleh dunia kerja yang mengglobal.

${ }^{25}$ Arifin, I. (2018, July). Nilai-Nilai Humanistik dalam Peningkatan Mutu Pendidikan di Era Globalisasi dan Revolusi Industri 4. In Prosiding Seminar Nasional Administrasi Pendidikan \& Manajemen Pendidikan (pp. 1-9). 


\section{Daftar Pustaka}

Andina, E. (2020). Eksplorasi Sikap Pembaca terhadap Wacana Kebijakan Program Pendidikan Kejuruan Empat Tahun. Aspirasi: Jurnal Masalab-masalah Sosial, 11(2), 135-155.

Afwan, M. (2013). Leadership on technical and vocational education in community college [Versielektronik]. Journal of Education and Practice, 4 (21), 21 23.

Arifin, I. (2018, July). Nilai-Nilai Humanistik dalam Peningkatan Mutu Pendidikan di Era Globalisasi dan Revolusi Industri 4. In Prosiding Seminar Nasional Administrasi Pendidikan \& Manajemen Pendidikan (pp. 1-9).

Brown, A., Kirpal, S., \& Rauner, F. (2007). Identitas at work. Netherlands: Springer.

Bukit, M. (2014). Strategi dan inovasi pendidikan kejuruan dari kompetensi ke kompetisi. Bandung: Alfabeta.

Depdiknas. 2003. Undang-undang RI Nomor 20, Tahun 2003, tentang Sistem Pendidikan Nasional

Divayana, D. G. H., Suyasa, P. W. A., Ariawan, I. P. W., Mahendra, I. W. E., \& Sugiharni, G. A. D. (2019, February). The design of digital book content for assessment and evaluation courses by adopting superitem concept based on Kvisoft Flipbook Maker in era of industry 4.0. In Journal of Physics: Conference Series (Vol. 1165, No. 1, p. 012020). IOP Publishing.

Edmon, A., \& Oluiyi, A. (2014). Re-engineering technical vocational education and training toward safety practice skill needs of sawmill workers against workplace hazards in Nigeria [Versi elektronik]. Journal of Education and Practice, 5(7), 150-157.

Himawati, I. P., Nopianti, H., \& Widiyarti, D. (2020). Sosialisasi Pengetahuan Mengenai Peluang dan Tantangan di Era Revolusi Industri 4.0 Pada Pelajardi Sekolah Menengah Atas dan Kejuruan di Kota Bengkulu. Widya Laksana, 9(2), 205-212.

Hiniker, L., \& Putnam, R. A. (2009). Partnering to meet the needs of a changing workplace. In International handbook of education for the changing world of work (pp. 203-217). Springer, Dordrecht.

Irianto, D. (2017). Industry 4.0 The Challenges of Tomorrow. Batu malang.

Kholiq, A. et al. (2020) Sosialisasi dan Pendampingan Siswa/Siswi Smk Teratai Putih Global 4 Dalam Menghadapi Revolusi Industri 4.0. Jurnal Abdimas USNI, 1(1).

Maysitoh, M., Agung, D. F., \& Afdal, A. (2018). Pendidikan Kejuruan di Era Industri 4.0: Tantangan dan Peluang Karier. SCHOULID: Indonesian Journal of School Counseling, 3(3), 89-96.

Mourtzis, D., Vasilakopoulos, A., Zervas, E., \& Boli, N. (2019). Manufacturing system design using simulation in metal industry towards education 4.0. Procedia Manufacturing, 31, 155-161.

Muhammad, Y. (2018). Era Industri 4.0: Tantangan dan Peluang Perkembangan Pendidikan Kejuruan Indonesia.

Prasetyo, A. (2019, May). Peran Pendidikan Kejuruan dalam Menghadapi Era Industri 4.0. In Seminar Nasional Pendidikan Teknik Otomotif (Vol. 3, No. 1).

PUTIH, S. S. T. Global 4 Dalam Menghadapi Revolusi Industri 4.0.

Rezasyah, T. (2018). Pelatihan Kesiapan Siswa SMK dalam Menghadapi Revolusi Industri 4.0. di SMK Global Mulia, Cikarang. Jurnal Pengabdian Kepada Masyarakat, 2(7), 526-529. 
Sudira, P. (2012). Filosofi \& Teori Pendidikan Vokasi dan Kejuruan. Yogyakarta: UNY Press.

Sutiyatno, S. (2015) 'Pentingnya pendidikan kejuruan berorientasi pasar tenaga kerja'.

Tilaar, H.A.R. (1998). Beberapa agenda reformasi pendidikan nasional dalam perspektif abad 21. Penerbit Tera Indonesia.

Wonggo, D. (2012). Tantangan Pendidikan Kejuruan dalam Era Perdagangan Bebas. Prosiding APTEKINDO, 6(1).

Kennedy, O.O. (2011). Philosophical and sociological overview of vocationaltechnical education in Nigeria [Versi elektronik]. Journal of Academic Research in Business and Social Sciences, 1, 167-175. 